\title{
O FENÔMENO DA ALUSĀO E O ENSINO/APRENDIZAGEM DE LÍNGUAS
}

José Carlos Chaves da CUNHA

Departamento de Línguas e Literaturas Estrangeiras. Centro de Letras e Artes. Doutor em Lingüística.

Il s'agit ici de dégager quelques caractéristiques de l'allusion - à partir de l'analyse d'un certain nombre d'occurrences de ce phénomene - afin de propose des modèles d'activités susceptibles d'attirer l'attention des (futurs) formateurs sur l'omnipresence des contenus implicites (en particulier, des conten) formateurs sur l'utilisation ordinaire d'une langue naturelle et der, des contenus allusifs) dans la prise en compte systématique de l'indirection du langage limportance de l'élaboration de matérie langage aussi bien lors de langues.
le matériel pédagogique que lors de la préparation de cours de

Tomando-se como ponto de partida o fato de que a alusão é um fenômeno muito comum no uso natural da língua ${ }^{1}$ - tanto oral quanto escrita - e muito pouco "explorado" nos manuais de línguas (materna e estrangeira), tenta-se depreender algumas de suas características estudando uma grande variedade de ocorrências para, a partir daí, propor modelos de atividades suscetíveis de serem realizadas com proveito nos estágios de formação ou reciclagem de formadores e, também, claro, nos cursos de línguas.

Este trabalho, ainda no seu começo, é parte integrante de um projeto maior - Pragmática Lingüística e Didática das Línguas cujo ponto de partida é uma reflexão sistemática sobre determinadas teorias pragmático-lingüísticas e de seu interesse concreto na 1 Este fenômeno aliás ocorre tambén em outros sistemas semióticos: na música,
na pintura... 
formação e/ou reciclagem de formadores na área de ensino-aprendizagem de línguas.

A alusão (do lat. allusione) é um tipo de implícito cujo campo não é muito fácil de delimitar com exatidão. As definições de lexicógrafos, semanticistas e especialistas em pragmática lingüística, embora não necessariamente contraditórias, não parecem passíveis de serem unificadas por enfocarem este fenômeno de pontos de vista diferentes e com objetivos diversos.

Para os lexicógrafos (cf. Aurélio, Caldas Aulete, Robert, etc.), trata-se em geral:

- de uma referência (menção, relação) indireta (vaga, apenas esboçada) a pessoa(s), fato(s) ou coisa(s) levando o leitor (interlocutor) a completar por meio de idéias o pensamento sugerido;

- ou ainda de um dito crítico, de uma apreciação indireta a um fato ou personagem conhecidos que só alguns leitores ou ouvintes percebem.

Para alguns semanticistas (Rastier 1989:30, por exemplo), "uma alusão é uma instrução de encaminhamento a um interpretante externo, unidade semiótica qualquer, não necessariamente lingüística, que permite atualizar componentes semânticos (inerentes ou aferentes) do texto estudado".

Já para especialistas em pragmática lingüística, notadamente Kerbrat-Orecchioni (1986:44, 46/47), a alusão é um tipo particular de subentendido empregado em circunstâncias diversas mas relativamente precisas:

- enunciados de conteúdo chulo ou obsceno;

- enunciados que fazem referência implícita a um ou mais fatos particulares conhecidos por alguns dos protagonistas do intercâmbio verbal e somente deles, ou sobretudo deles, o que estabelece entre eles uma certa conivência (pacífica ou agressiva);

- enunciados que remetem a outros textos. “... o texto evocado e convocado pela alusão intertextual está, ao mesmo tempo, como o subentendido, presente e ausente daquele que o acolhe" (id:47).

Como nenhuma dessas definições parece suficiente para abarcar o fenômeno da alusão como um todo, tenta-se apreendê-lo melhor a partir de uma reflexão assentada na análise de, aproximadamente, uma centena de ocorrências consideradas a priori como alusivas e em estudos lingüístico-pragmáticos de Grice, Récanati, Ducrot et Kerbrat-Orecchioni, dentre outros.

A alusão é um tipo de implícito por não constituir, em princípio, o objeto do dizer. O exemplo infra esclarece o que se entende por isso.

Ex.: "O real era um cilindro oco e profundo, onde a água, a terra e o ar se combinavam para formar tudo o que existia. As rãzinhas aprendiam que o seu era o melhor dos mundos e, na escola, aprendiam a recitar:

"Rãzinha, não verás buraco algum como este

Ama, com orgulho, o buraco em que nasceste. .."

(Rubem Alves, "O Pintassilgo e as Ras")

A referência ao poema $A$ Pátria de Olavo Bilac apesar de bem transparente, não está explicitada no texto, não é, em princípio, o objeto do dizer. Por outro lado, como o conteúdo alusivo do texto supra não pode ser descodificado apenas com base na competência lingüística do sujeito falante, não se pode caracterizar o fenômeno como um tipo particular de pressuposição. Resta portanto considerá-lo - como o faz aliás Kerbrat-Orrecchioni (cf. supra) - um tipo de subentendido uma vez que, para ser atualizado, necessita, não somente da competência lingüística do sujeito falante, como também de sua competência enciclopédica além de, freqüentemente, suas competências lógica e retórico-pragmática.

Uma outra característica do fenômeno é a intencionalidade do sujeito que produz o texto alusivo. De fato, a comunicação discursiva se dá de um modo tal que não se pode dissociar o que é comunicado do fato de que este conteúdo (ou pelo menos parte dele) é sempre comunicado intencionalmente. É evidente que esta característica não é específica ao texto alusivo. Anscombre (1980:65) chega a considerar que o sentido de um enunciado se reduz às intenções que apresenta como tendo motivado sua enunciação. Trata-se entretanto de uma característica constitutiva do fenômeno que, embora não permita distingui-lo de todos os tipos de subentendido (da insinuação, por ex.), distingue-o de, pelo menos, um tipo de conteúdo implícito: aqueles que Récanati agrupa sob a rubrica "Deixar entender". É que, para este pesquisador (cf. 1981:100), deixar entender, contrariamente a dar a entender, 
não coloca necessariamente em jogo uma intenção comunicativa particular do locutor; para dar a entender é necessário fazer a enunciação $\mathrm{E}$ com a intenção de comunicar o que esta enunciação deixa entender. Em outras palavras, é necessário fazer com que a intenção de comunicar seja aberta, pública e objetivamente determinável. Conseqüentemente, para que possa haver subentendido alusivo num determinado texto, é indispensável que haja não apenas a intenção, por parte do locutor, de veicular dessa maneira um determinado conteúdo, mas também que essa intenção possa ser captada pelo interlocutor. Caso contrário, a alusão não é atualizada.

A intencionalidade do locutor/escritor portanto não pode ser desvinculada de sua apreensão pelo interlocutor. Este, para que o conteúdo alusivo tenha existência real, isto é, seja atualizado, precisa captá-lo a partir de certas marcas inscritas no texto (oral ou escrito). Estas marcas permitem-no, no mais das vezes, conciliar o texto produzido com o cotexto (coocorrentes textuais) e com o contexto de enunciação. Cabe no entanto frisar que, isoladamente, nem a intencionalidade, nem este esforço de conciliação são suficientes (embora sejam necessários!) para a apreensão de um conteúdo alusivo. Ambos são características constitutivas da alusão.

Por ser um tipo de subentendido, um tipo de implicatura segundo a terminologia de Grice, a alusão se caracteriza também pelo fato de não possuir vínculo com os valores de verdade, nem com a forma lingüística. Como todo e qualquer conteúdo subentendido (cf. Armengaud, 1985:68), ela não é lógica no sentido estrito, nem lingüística. Ela é discursiva e contextual, e se assenta no que é pensado a partir, ao mesmo tempo, do que é dito e da situação comum aos interlocutores - na qual isto é dito. Observe-se, por exemplo, o seguinte texto:

"Piada brasiliense. Já está definido o papel do triunvirato de oposiçōes no debate sobre a reforma fiscal. Orestes Quércia vai colaborar no combate à sonegação, Tasso Jereissati escreverá um capítulo sobre notas frias e Lula irá formular um plano para o IPTU" (VEJA - 8/7/92 p.39).

A alusão aí não é função da veracidade (ou não) do que é dito, nem de sua forma lingüística. Mas da relação do que é dito com o contexto situacional que deve ser partilhado pelos interlocutores. Daí porque o sentido desse texto, a piada, só poderá ser apreendido por quem, pelo menos, souber que se discute no Congresso o projeto de reforma fiscal e que Quércia, Tasso e Lula, líderes de três dos maiores partidos políticos de oposição no Brasil na época (respectivamente, PMDB, PSDB e PT), tiveram problemas com pagamento de impostos: o primeiro foi acusado de sonegar o imposto de renda, o segundo teve suas empresas passadas "ao pente fino" pela receita federal e o terceiro, por ser o presidente do partido da ex-prefeita de São Paulo, se viu envolvido com o problema de cobranças de IPTU consideradas por demais elevadas por muitos contribuintes.

Ao lado dessas características constitutivas do fenômeno da alusão há ainda muitas outras que, pouco a pouco, estão sendo depreendidas da análise do corpus e sistematizadas. Apresenta-se a seguir, rapidamente, duas ou três delas ressaltando-se, mais uma vez, que o trabalho está somente no seu início.

De um modo geral, é possível considerar que a alusão está vinculada à atualidade. Os casos de alusão até agora estudados inclusive os não extraídos de revistas e jornais recentes - tendem a confirmar a hipótese segundo a qual o conteúdo alusivo de muitos textos deixa de existir quando estes são lidos ou analisados fora (bastante tempo depois) de seu contexto de produção. Isto se explica, talvez, através de uma outra característica da alusão: a de que ela, mais do que os outros tipos de implícito, apela sempre para um saber extra-enunciativo, está sempre assentada no conhecimento partilhado. Quanto maior e mais preciso é este conhecimento partilhado (entre os agentes de um intercâmbio lingüístico) mais evidente se torna o conteúdo alusivo de um texto. Compare-se a série de exemplos infra, extraídos de diferentes números da revista VEJA (que explora bastante o fenômeno da alusão nos títulos de seus artigos):

1. "O Choro e Você, Tudo a Ver" (1/4/92 p. 90) - título calcado no slogan da Rede Globo de televisão (A Globo e você, tudo a ver): alusão à tendência dessa rede para provocar a emoção, o choro, em seu Jornal Nacional;

2. "L'Année Dernière à Araxá (6/5/92 p.13) - título alusivo às últimas férias do ex-Presidente Collor calcado no cine-romance de Alain Robbe-Grillet (L'Année Dernière à Marienbad);

Moara - Rev. do Curso de Mestr., Belém, n.1: 85-95, mar./set., 1993 
3. "Ligaçōes Censuradas" (27/5/92 p.65) - a esposa de um ministro de Collor assumiu a função de controlar as ligações telefônícas do marido. Ela só passava o telefonema para o marido sem exigir prévia identificação do interlocutor quando se tratava de voz masculina. Alusão a "Ligações Perigosas", célebre romance de C. de Laclos?!

Parece claro, intuitivamente, que o grau de evidência do conteúdo alusivo é muito maior no exemplo $\mathrm{n} .1$ do que no $\mathrm{n} .2$ e neste do que no de n. 3. No último exemplo, aliás, parece lícito inclusive questionar se se trata realmente de uma alusão, se houve, de fato, intencionalidade por parte do jornalista que escreveu o texto apesar dessa obra ter recentemente se tornado bastante conhecida graças às suas versōes para o cinema.

Isto permite que se postule a existência de diferentes "graus" de alusão segundo dois eixos:

- um que reflete o grau de certeza, por parte do leitor/ouvinte, da intencionalidade do locutor/escritor: a alusão no texto "piada brasiliense" parece, a princípio ${ }^{2}$, bem mais clara do que a do ex. 3 supra;

- e outro que reflete o nível de "apreensão" do conteúdo alusivo pelo ouvinte/leitor: nos ex. supra, o de n. 1 parece ${ }^{2}$ mais evidente do que o de n. 2 .

É importante notar que, apesar da onipresença dos conteúdos implícitos na comunicação humana, apesar da grande freqüência (e da extensão) dos conteúdos alusivos nos intercâmbios lingüísticos, o fenômeno da alusão é ainda muito pouco estudado e, até hoje, praticamente ignorado em sala de aula. Perdura uma distância muito grande entre sua freqüência de uso - tanto na língua oral quanto na língua escrita - e sua "exploração" nos manuais e cursos de língua (materna ou estrangeira). De onde se deduz que as pessoas que acabam aprendendo a utilizar com propriedade a indireção da linguagem e, em particular, a alusão, aprenderam a fazê-lo da mesma maneira como assimilaram os demais mecanismos lingüísti-

2 E evidente que, em última análise, os "graus" são funçáo de cada ouvinte (leitor), de seu conhecimento de mundo e, principalmente, do conhecimento que partilha com o locutor/escritor. cos: por impregnação, intuitivamente, interiorizando - às vèzes abusivamente - regras de funcionamento da língua.

Poder-se-ia até pensar - e há quem o faça - que se o emprego da alusão é generalizado num grande número de línguas e culturas (senão em todas!), se as pessoas aprenderam naturalmente a utilizar este recurso de maneira adequada, não é necessário que ele seja "explorado" na escola.

É claro que este não é o ponto de vista aqui defendido pois isto equivaleria a dizer, por exemplo, que não se deve ensinar/ aprender língua materna em sala de aula já que os alunos que a freqüentam sabem utilizá-la com propriedade na maioria das situações de comunicação. Ou então, que só se deve ensinar a modalidade escrita da língua materna na escola, e apenas no 10 grau, porque, depois, os alunos não precisam mais aprender a escrever. Nossa hipótese, pelo contrário, é que quanto mais e melhor se conhecem os fenômenos lingüísticos, seus mecanismos de funcionamento, tanto mais e melhor se pode empregá-los. Daí o interesse que deve ter o professor de língua na compreensão do fenômeno alusivo, de seus mecanismos de funcionamento a fim de ajudar seus alunos a empregá-los de maneira cada vez mais sistemática e adequada às diferentes situações de comunicação.

Não se quer dizer com isso que a alusão deva ser tópico específico e isolado de um programa de ensino/aprendizagem da língua materna ou estrangeira. Pelo contrário, acha-se que deva estar integrada aos outros fenômenos característicos da indireção da linguagem num programa que privilegie - pelo menos em nível de 1 ? grau - o ensino-aprendizagem, não sobre a língua, mas da e na língua respeitando os parâmetros ligados às diferentes situações de comunicação.

No que concerne ao futuro formador, entretanto, parece ser útil um trabalho de sensibilização aos fenômenos inferenciais, notadamente, aqui, os alusivos, através de atividades suscetíveis de levá-los a uma melhor compreensão de seus mecanismos de funcionamento e de sua importância para o ensino/aprendizagem de línguas.

Uma vez atingido este objetivo, será mais fácil e produtivo propor-lhes - a título, sempre, de exemplo - outras atividades, talvez menos específicas, tendo como pano de fundo a Pragmática 
Lingüística, só que destinadas a serem realizadas com seus respectivos alunos.

Este tipo de abordagem que privilegia um vaivém constante entre teoria e prática já foi testado com formadores - mestrandos de Lingüística da UFPA - e com alguns alunos destes, tendo alcançado uma receptividade tal que serviu de base para o prosseguimento do trabalho e para a montagem, com a colaboração de alguns colegas, de um curso de Especialização de Ensino/Aprendizagem do Português Língua Materna.

Evidentemente que, para uma sensibilização voltada apenas para o fenômeno da alusão e seus mecanismos de funcionamento, seria impossível se apresentar aqui atividades já prontas, estruturadas, experimentadas, uma vez que - como já foi dito supra - a pesquisa ainda está no início. As que seguem - voltadas para o formador - têm um caráter provisório, se inspiram em Cunha (1991) e são apresentadas a título de exemplo.

1. Identifique, dentro dos enunciados abaixo, os que veiculam um conteúdo alusivo, explicitando a alusão e dizendo por que foi capaz de explicitá-la:

- Brésil: l'assassinat de Chico Mendes

Les tueurs de la Forêt (Le Monde, 30/12/88)

- Amazonie: les saigneurs de la terre

(Le Nouvel Obs. 13/4/89)

- La Magie Noir (Nouvel Obs. 13/4/89)

- Météorologie tchèque: avant le Nouveau Printemps de fortes perturbations (Le Canard Enchaîné 22/11/89)

- Ceaucescu: le génie des quatre pattes

Objetivos: (Le Canard Enchaîné 22/11/89)

- mostrar como as leis do discurso intervém, durante o processo interpretativo, essencialmente para solicitar a emergência de um determinado número de inferências e "normalizar", do ponto de vista retórico-pragmático, um enunciado aparentemente transgressivo;

- reconhecer a importância da competência enciclopédica, do conhecimento partilhado, na identificação e descodificação de conteúdos alusivos.
2. Destaque, no documento em anexo, pelo menos duas alusões. Identifique seu(s) tipo(s) de "amarração" lingüística.

3. a) Traduza os seguintes enunciados:

- Ceaucescu: le génie des quatre pattes

- Amazonie: les saigneurs de la terre

b) Algum conteúdo (alusivo) veiculado por estes enunciados foi “apagado" na tradução? Qual(ais)?

Objetivos:

- mostrar como os conteúdos alusivos estão ligados a uma língua e a uma cultura; sivos;

- apresentar alguns tipos de "amarração" dos conteúdos alu-

- mostrar que interpretamos os enunciados (inclusive os alusivos) de modo que sejam coerentes com o que sabemos do universo;

- demonstrar o quanto a emergência de um conteúdo alusivo depende do contexto enunciativo e das diferentes competências do sujeito falante.

4. Reescreva o texto em anexo explicitando o maior número possível de conteúdos por ele veiculados.

5. Procure um co(n)texto para os seguintes enunciados:

- És realmente filha de tua mãe

- O jeito é imitar o P.C.

- Estás precisando de muito abacate.

Objetivos:

- mostrar que a alusão está ligada à atualidade, e que está assentada no conhecimento partilhado;

- mostrar a importância das leis do discurso e da teoria das faces nos conteúdos alusivos.

Nesta (não tão) breve exposição muita coisa foi, inevitavelmente, deixada de lado, em parte por falta de tempo e em parte por estarem ainda os estudos em fase embrionária. Por exemplo:

- uma apresentação mais sistematizada de mecanismos interpretativos da alusão: o papel do conhecimento partilhado (evocado muito superficialmente), a importância - fundamental - do contexto, o funcionamento das regras sociais e discursivas (explicadas pelas leis do discurso, teoria da preservação das faces, etc.)...; 
- um estudo sistematizado sobre os diferentes tipos de "amarração" lingüística dos conteúdos alusivos: entoacional, ortográficofonética, sintagmática, sintática, léxico-semântica;

- uma delimitação mais precisa dos "espaços" privilegiados da alusāo (o sexual, o político, o esportivo. . .);

- um estudo dos tipos de relação possíveis entre as noções de alusão e as noções de intertexto, argumentação, polifonia, etc. . .

Teria sido interessante apresentar ainda:

- um corpus expressivo de ocorrências do termo alusão, seus derivados (formas do verbo aludir) e eventuais sinônimos (referir, evocar...) a fim de melhor apreender seus sentidos usuais e sua área de abrangência;

- um estudo da alusão como possível fonte de neologismos (ex. marajá, máfia. ..);

- e, principalmente, propostas de atividades concretas, ordenadas e sistematizadas em sala de aula suscetiveis não apenas de conscientizar os alunos da onipresença dos conteúdos implícitos em particular os alusivos - em nosso dia-a-dia, mas também, sobretudo, ajudá-los a compreendê-los, interpretá-los e produzi-los de maneira eficaz.

Esta enumeração do que ainda se pode (deve) fazer para compreender melhor, explicitar e "explorar" os mecanismos constitutivos da alusão já se apresenta, de certo modo, como um "mapa da mina". . . alusão a filmes (e novelas!) de aventuras onde há riquezas a serem descobertas mas, também, inevitáveis obstáculos a serem transpostos durante o percurso. Agora é procurar não perder a trilha...

\section{REFERÊNCIAS BIBLIOGRÁFICAS}

ANSCOMBRE, Jean-Claude - Voulez-vous dériver avec moi? in Communications, n. 32. Paris, Ecole des Hautes Etudes en Sciences Sociales, 1980.

ARMENGAUD, Françoise - La Pragmatique. Paris, PUF, 1985.

CUNHA, José Carlos C. da - Pragmática Lingüística e Didática das Línguas. Belém, Ed. Universitária UFPA, 1991.

KERBRAT-ORECCHIONI, Catherine - L'Implicite. Paris, A. Colin, 1986.

RASTIER, François - Sens et Textualité. Paris, Hachette, 1989.

RECANATI, François - Insinuation et Sous-Entendu, in Communications n. 30, Paris, Seuil, 1979. 